\title{
Progress in Clinical Neurosciences: Migraine-Stroke: A Causal Relationship, but Which Direction?
}

\author{
Ralph Z. Kern
}

\begin{abstract}
A significant association between migraine and ischemic stroke has been demonstrated in population and case-control studies. The risk of ischemic stroke appears to be higher in migraine with aura (MWA) than migraine without aura (MwoA). Migraine-stroke comprises a number of distinct entities, including migrainous infarction, in which ischemic stroke occurs during an attack of MWA and migraine-related stroke, in which the causal link is less clear. Migrainous infarction accounts for only one-third of migraine-stroke, strokes may occur during attacks of MwoA, and a number of cerebrovascular disorders may present as MWA or MwoA. Migraine may occur as a consequence of conditions that are known to cause stroke; therefore it remains to be determined whether migraine predisposes to stroke in the absence of any known disease associations, if it is an epiphenomenon of an underlying stroke diathesis, or if it requires the presence of another stroke risk factor to produce cerebral ischemia. Furthermore, it is unclear if ischemia results in migraine more often than migraine results in ischemia. Careful clinical studies that evaluate this bidirectional relationship are needed to determine why migraine patients are subject to a higher risk of ischemic stroke.
\end{abstract}

\begin{abstract}
RÉSUMÉ: Migraine - accident vasculaire cérébral: une relation causale, mais dans quelle direction? Des études de population et des études cas-témoin ont montré une association significative entre la migraine et l'accident vasculaire cérébral ischémique (AVCI). Le risque de faire un AVCI semble plus élevé dans la migraine avec aura (MAA) que dans la migraine sans aura (MSA). La migraine - AVC comprend plusieurs entités distinctes dont l'infarctus migraineux dans lequel l'AVCI survient pendant une crise de MAAet la migraine reliée à l'AVC dont le lien causal est moins clair. L'infarctus migraineux explique seulement le tiers des cas de migraine - AVC. Un AVC peut survenir pendant une crise de MAA et certains troubles vasculaires cérébraux peuvent avoir un mode de présentation semblable à celui de la MAA ou de la MSA. La migraine peut survenir comme conséquence de pathologies reconnues comme causant l'AVC. Il reste donc à déterminer si la migraine prédispose à l'AVC en l'absence d'une association connue avec une autre maladie, si c'est un épiphénomène d'une diathèse sous-jacente d'AVC ou si la présence d'un autre facteur de risque d'AVC est nécessaire pour produire une ischémie cérébrale. Il faudrait effectuer des études cliniques minutieuses évaluant cette relation bidirectionnelle pour déterminer pourquoi les patients migraineux sont à plus haut risque d'AVCI.
\end{abstract}

Can. J. Neurol. Sci. 2004; 31: 451-459

The association between migraine attacks and permanent neurological deficits has been recognized since the original description of persistent visual deficits by Féré in $1861^{1}$ and Galezowski in $1881 .^{2}$ Féré described 10 cases, of which four were left with permanent deficits that included hemianopia (3) and aphasia (1). The term 'complicated migraine'was coined by Charcot in $1890 .^{3}$ Subsequently in 1915 , Hunt ${ }^{4}$ expanded the range of neurological deficits associated with a migraine attack to include permanent paralysis.

More recently a wide range of descriptive terminology has emerged to define the complex relationship between migraine and stroke. This includes: 'active migraine and stroke', 'migrainous infarction', ${ }^{6}$ 'migraine-induced stroke' and 'migraine-related stroke'. 7 The definitions describe a causal spectrum that includes: migrainous infarction, in which the clinical deficit arises out of the migraine aura $;{ }^{8}$ migraine-induced stroke, in which the stroke occurs during a migraine attack, but not necessarily related to the aura; and migraine-related stroke, in which the causal linkage is less clear. In the case of 'active

From the Division of Neurology, Mount Sinai Hospital, Toronto, Ontario, Canada ReCEIVED JAN 23, 2004. ACCEPTED INFINALFORM MAy 6, 2004.

Reprint requests to: Ralph Z. Kern, Division of Neurology, Mount Sinai Hospital, 431600 University Ave, Toronto, Ontario M5G 1X5 Canada 
migraine and stroke', the authors have specified that the subject experience 'at least two migraine attacks in the previous two months before the acute stroke onset'.

Not all strokes that occur within the context of a migraine attack are causally linked to migraine with aura (MWA). For example, Hoekstra-van Dalen et $\mathrm{al}^{9}$ studied 14 patients with cerebral infarction accompanying migraine and found that the neurological deficit was similar to previous auras in only three patients. In a case series reported by Milhaud et al, ${ }^{5} 15$ of 24 subjects who experienced strokes during migraine attacks, did so during attacks of migraine without aura (MwoA). In response to these clinical observations, Welch and Levine ${ }^{10}$ suggested that the term 'migrainous infarction' should be redefined in the IHS classification as a complication of MWA and MwoA.

The relationship between migraine and stroke is further complicated by reports of stroke-induced migraine ${ }^{11,12}$ and the frequent occurrence of headache at stroke onset. ${ }^{13}$ In fact, some authors have questioned whether migraine and stroke are two common but independent disorders or whether they share a commonality of cause. ${ }^{14}$ In the present review, the epidemiology and pathophysiology of migraine-stroke will be analyzed. It will be argued that the relationship between migraine and stroke is complex, bidirectional, and may be mediated by a common underlying cause.

\section{EPIDEMIOLOGY}

Migraine appears to be an important cause of occipital ${ }^{5,9,15,16}$ and cerebellar ${ }^{17}$ infarction, however involvement of the middle ${ }^{5}$ and anterior ${ }^{18}$ cerebral artery territories has also been reported. A significant nonrandom relationship between migraine and stroke has been demonstrated in several large population and casecontrol studies. In five large population databases, ${ }^{19-23}$ the adjusted relative risk of clinical stroke in migraine subjects ranged from 1.7-2.1 and the adjusted hazard ratio ranged from 1.5-1.8 (Table 1). This compares in magnitude to an adjusted relative risk of stroke associated with hypertension of $2.1(95 \%$ CI 1.7-2.7). ${ }^{19}$ Five hospital-based case control studies examined the relationship of migraine and stroke ${ }^{24-28}$ (Table 2). Schwaag et $\mathrm{al}^{26}$ calculated a summary odds ratio of 2.1 (95\% CI 1.7-2.6). This is similar in magnitude to the relative risk observed in population studies and is independent of other stroke risk factors such as age, hypertension, smoking, oral contraceptive use, and gender.

One study that looked at headache, rather than migraine, observed a lower adjusted stroke risk. ${ }^{22}$ According to Merikangas et al, ${ }^{19}$ the higher stroke risk associated with migraine extends past the age of 60, although a smaller case-control study suggested that migraine was not a significant stroke risk factor in patients over the age of $60 .{ }^{29}$ The higher stroke risk is unrelated to the use of triptans. ${ }^{30}$ Therefore, a significant non-random association between migraine and stroke has been clearly established in individuals less than 60 years of age. The relative contribution of migrainous infarction and MWA must be understood in order to further define this risk at the individual patient level.

\section{Migrainous infarction}

Migrainous infarction (IHS classification 1.6.2), ${ }^{31}$ specifies that the subject have a history of previous episodes of migraine with aura and that the neurological deficit occurs in the same vascular distribution as the aura. Since the migraine aura may be prolonged and continue for up to seven days,${ }^{32}$ the IHS definition requires that the deficit persist beyond seven days. Welch's definition of migraine-induced stroke $^{33}$ requires that the neurological deficit must exactly mimic the migrainous

\section{Table 1. Population studies of migraine stroke risk.}

\begin{tabular}{|c|c|c|c|c|c|}
\hline Study & Study Design & Diagnosis & $\mathbf{N}$ & $\begin{array}{l}\text { Risk for } \\
\text { ischemic stroke }\end{array}$ & $95 \% \mathrm{CI}$ \\
\hline $\begin{array}{l}\text { Merikangas et al }{ }^{19} \\
\text { (National Health and }\end{array}$ & $\begin{array}{l}\text { Prospective baseline and first follow-up data } \\
\text { rition Examination Survey) }\end{array}$ & Migraine & 14,407 & $2.1(\mathrm{RR})$ & $1.5-2.9$ \\
\hline $\begin{array}{l}\text { Velentgas et al }^{20} \\
\text { (United Healthcare/ } \\
\text { Ingenix Research } \\
\text { Database (UHC), US }\end{array}$ & Retrospective cohort & Migraine & 130,411 & $1.7(\mathrm{RR})$ & $1.3-2.1$ \\
\hline $\begin{array}{l}\text { Hall et al }{ }^{21} \\
\text { (General Practice } \\
\text { Research Database } \\
(G P R D, U K)\end{array}$ & Retrospective cohort & Migraine & 63,575 & $\begin{array}{l}1.5 \text { (AHR, } \\
\text { non-triptan users) }\end{array}$ & $1.3-1.8$ \\
\hline $\begin{array}{l}\text { Jousilahti et } \mathrm{al}^{22} \\
\text { (Finnish population) }\end{array}$ & Prospective observational cohort & Headache & 35,056 & $\begin{array}{l}\text { Males } 1.8(\mathrm{AHR}) \\
\text { Females } 1.12(\mathrm{AHR})\end{array}$ & $\begin{array}{l}1.3-2.7 \\
0.7-1.8\end{array}$ \\
\hline $\begin{array}{l}\text { Buring et al }{ }^{23} \\
\text { (Physician's Health } \\
\text { Study, US) }\end{array}$ & Prospective observational cohort & Migraine & $\begin{array}{l}22,071 \\
(1479 \mathrm{~m}\end{array}$ & $2.0(\mathrm{RR})$ & $1.1-3.6$ \\
\hline
\end{tabular}

Abbreviations: AHR-adjusted hazard ratio; RR-relative risk.; CI-confidence interval 
Table 2. Case-control studies of migraine as a risk factor for ischemic stroke.

\begin{tabular}{|c|c|c|c|c|c|}
\hline Study & Migraine & Controls & Odds ratio of migraine in ischemic stroke $(95 \% \mathrm{CI})$ & MwoA & MWA \\
\hline Tzourio et $\mathrm{al}^{27}$ & 212 & 212 & $\begin{array}{l}1.3(0.8-2.3) \text { all subjects } \\
4.3(1.1-21.4) \mathrm{F}<45 \text { years }\end{array}$ & NA & NA \\
\hline Carolei et $\mathrm{al}^{24}$ & 308 & 591 & $\begin{array}{l}1.9(1.1-3.1) \text { all } \\
2.5(1.2-4.9)<35 \text { years } \\
1.3(0.7-2.4)>35 \text { years }\end{array}$ & $1.5(0.9-2.5)$ & $5.2(1.4-20.0)$ \\
\hline Schwaag et $\mathrm{al}^{26}$ & 160 & 160 & $\begin{array}{l}2.1(1.2-3.8) \text { all subjects } \\
2.7(1.2-5.7) \mathrm{F}<45 \\
3.3(1.3-8.0) \mathrm{F}<35 \text { years } \\
1.4(0.6-3.2) \mathrm{F}>35 \text { years }\end{array}$ & $2.5(1.3-6.3)$ & $1.0(0.3-3.6)$ \\
\hline
\end{tabular}

Abbreviations: RR- Relative Risk; 95\% CI- 95\% Confidence Interval; MWA- Migraine with Aura; MwoA- Migraine without Aura; NA-not analyzed; F-females.

symptoms preceding the attack and that all other causes of stroke be excluded, although risk factors such as hypertension, diabetes, mitral valve prolapse or use of oral contraceptives would not be a cause for exclusion.

A number of investigators have estimated the incidence of migrainous infarction in stroke databases ${ }^{6,19,34-36}$ (Table 3). The pooled results indicate that migrainous infarction accounts for approximately $0.5-1.4 \%$ of all new strokes. In the Oxfordshire Community Stroke Project, ${ }^{37}$ only a minority (3/7) of subjects with 'migrainous infarction'were free of other known stroke risk factors. Migrainous infarction is estimated to account for 10$14 \%$ of 'young strokes' (less than 45 years) ${ }^{6,38}$ and approximately $1 / 3$ of migraine-related stroke. ${ }^{25}$ Based on these observations, it may be concluded that migrainous infarction does not account for all strokes occurring during migraine attacks, and accounts for only a minority of migraine-related strokes.

\section{MWA and migraine-stroke}

There is a wide range of MWA prevalence estimates due to variable use of IHS criteria and other methodological factors such as the length of the observation period. In a recent large population study in the Netherlands, up to $1 / 3$ of migraine subjects experienced attacks that included aura within the preceding year. ${ }^{39}$ The prevalence of MWA appears to be higher in migraine-stroke subjects than in matched control migraineurs. $^{40}$ Four case-control studies (Table 2) have demonstrated a higher stroke risk associated with MWA compared to MwoA. ${ }^{24-26,28}$ Donaghy et $\mathrm{al}^{41}$ analyzed specific MWA characteristics that increase the risk of stroke and concluded that migraine duration of more than 12 years (odds ratio=4.6), onset as MWA (odds ratio=8.4), and attack frequency of greater than 12/year (odds ratio $=10.4$ ) were significant risk factors for stroke. Therefore, it can be concluded that MWA carries a higher stroke risk than MwoA and that specific MWA characteristics appear to be important determinants of that risk. It is still not clear if MWA and MwoArepresent distinct disorders or are clinical expressions along a biological continuum. ${ }^{42}$

The association of MWA and migrainous infarction is confounded by the occurrence of prolonged auras (longer than one hour and less than seven days) in $20 \%$ of attacks. ${ }^{43}$ Further complicating this association is the observation that MWA occurs within a diverse biological continuum that includes: familial hemiplegic migraine; ${ }^{44}$ basilar artery migraine; ${ }^{45}$ MELAS $;{ }^{46}$ HaNDL syndrome; ${ }^{47}$ and CADASIL. ${ }^{48}$ Furthermore, the relative importance of MWA in migrainous infarction is a matter of controversy. Whereas Linetsky et $\mathrm{al}^{35}$ observed that all six subjects with migrainous stroke had MWA, most case series have come to a different conclusion. Rothrock et $\mathrm{al}^{49}$ described the occurrence of ischemic stroke in five patients with 'common' migraine. Narbone et $\mathrm{al}^{50}$ reported two patients with a history of MwoA who experienced cerebral infarction during attacks of MwoA. Saquegna et $\mathrm{al}^{38}$ reported a case series in which 'migrainous stroke' was defined as a 'sudden-onset focal neurological deficit not fully reversible within seven days and/or associated with neuroimaging confirmation of cerebral infarction - occurring during a common migraine attack or following the

Table 3. Incidence of migrainous infarction (\% of new strokes).

\begin{tabular}{lrc}
\hline Study & N & $\begin{array}{l}\text { Incidence of migrainous infarction } \\
\text { (\% of new strokes) }\end{array}$ \\
Kittner SJ et al $^{34}$ & 428 & $1.4 \%$ \\
Sochurkova D et al $^{36}$ & 2389 & $0.5 \%$ \\
Arboix A et al $^{6}$ & 2000 & $0.77 \%$ \\
Linetsky et al $^{35}$ & 750 & $0.8 \%$ \\
\hline
\end{tabular}




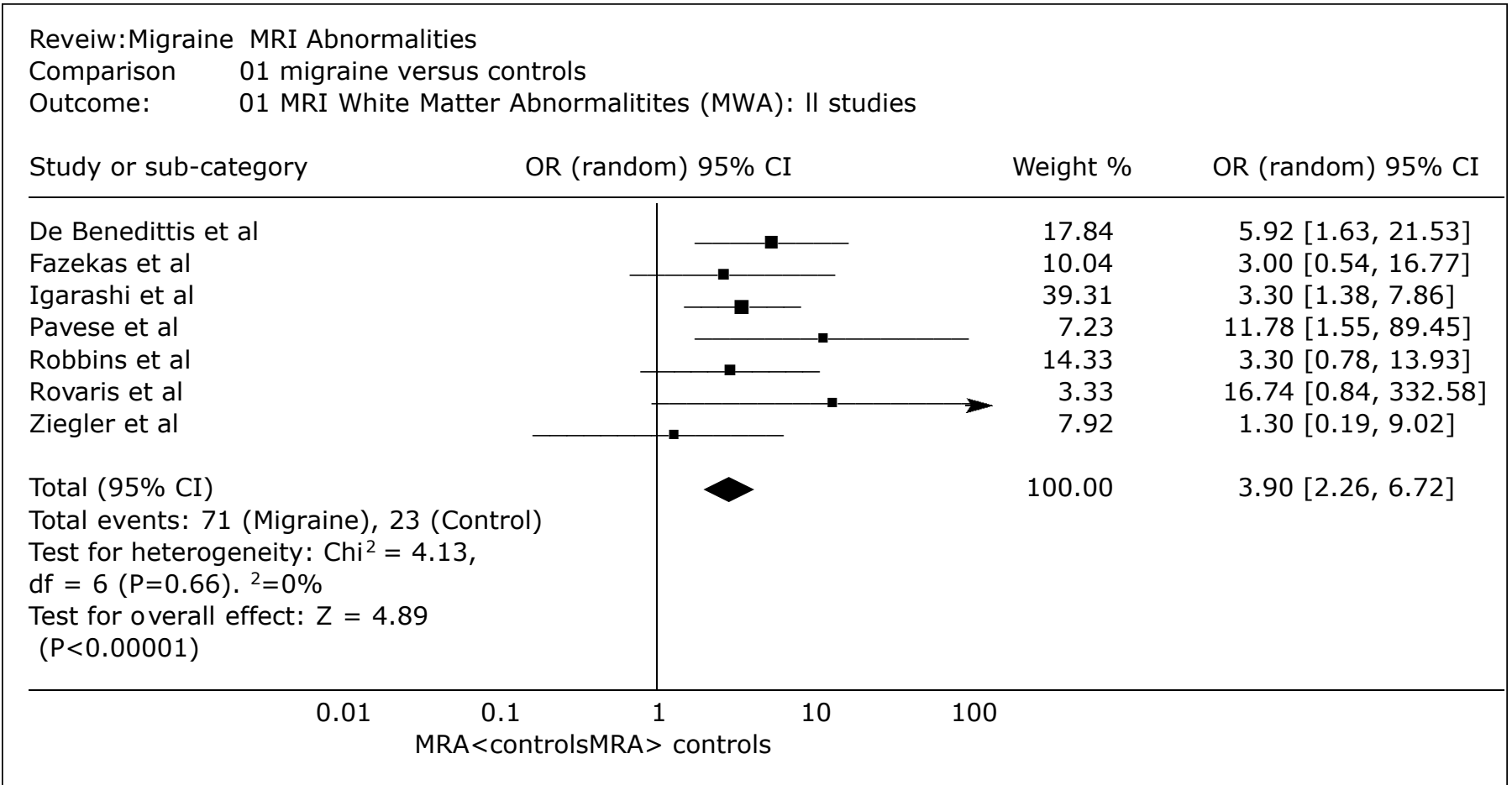

Figure: Plot of odds ratios and 95\% confidence intervals.

From Swartz, R, Kern R. Migraine is associated with MRI white matter abnormalities: a meta-analysis. Arch Neurol 2004;61:1366-1368.

neurological symptoms of classic migraine'. In this case series, $5 / 6$ strokes occurred during an attack of 'common migraine'. Milhaud et $\mathrm{al}^{5}$ also noted that only nine of 24 strokes arising from a migraine attack occurred in the context of MWA.

It is unclear if the simultaneous occurrence of MWA or MwoA and stroke represents a migrainous infarction since migraine headaches may occur during acute stroke ${ }^{11}$ and MWA may be the presenting manifestation of a diverse group of disorders including: occipital ${ }^{51}$ and brainstem $^{52}$ arteriovenous malformations; occipital lobe tumors; ${ }^{53}$ subarachnoid hemorrhage; ${ }^{54}$ occipital lobe epilepsy $;^{55}$ radiation-induced ${ }^{56}$ and post-partum ${ }^{57}$ cerebral vasculopathy; moyamoya disease $;^{58}$ and basilar artery dissection. ${ }^{59}$

Shuaib $^{60}$ cautioned against the uncritical use of the term migraine-stroke in a case series in which five subjects identified as suffering from migraine-stroke were found to have other significant stroke etiologies, including arterial dissection, endocarditis, and atherosclerosis. A recent case-control study by Tzourio et $\mathrm{al}^{61}$ observed that MwoAis more common in subjects with cervical artery dissection compared to hospitalized controls, further supporting the hypothesis that an underlying arterial wall disease may be a predisposing condition for migraine. The diagnosis of dissection must be made with caution as migrainous arterial spasm may be confused with dissection on angiography. ${ }^{6}$

In a recent case-series, Olesen et $\mathrm{al}^{63}$ have suggested that 'ischemia-induced migraine attacks may be more frequent than migraine-induced ischemic insults'. Therefore, migraine may occur as a consequence of stroke, stroke may occur as a consequence of migraine, and both may occur as a result of other pathologies. Conclusions from epidemiological studies are limited by these complex relationships and the multiplicity of definitions in common usage. Greater understanding of the pathophysiology of migraine-stroke is needed before directionspecific causation may be implied.

\section{Pathophysiology}

A practical conceptual framework of migraine-stroke pathophysiology must take into account the common occurrence of white matter signal abnormalities in migraine patients, the possibility that stroke may arise from the putative mechanisms of MWA, as well as the complex relationships between coagulation abnormalities, oral contraceptives, cardiac disorders and migraine.

\section{Magnetic resonance image white matter abnormalities in migraine: a marker for stroke?}

White matter abnormalities on magnetic resonance imaging (MRI) can be seen in migraine subjects; however they are also incidental findings in normal control populations. Magnetic resonance imaging white matter signal abnormalities are more common in individuals with cerebrovascular risk factors. ${ }^{64}$ There are conflicting studies showing either increased, ${ }^{65-68}$ or equal incidence ${ }^{69-71}$ of MRI white matter abnormalities in subjects with migraine compared to those without migraine. Studies that report no increased incidence of MRI white matter abnormalities imply 
that the reported increase can be accounted for by disease comorbidities, such as age, hypertension, diabetes or demyelinating diseases. A recent meta-analysis by Swartz and Kern ${ }^{72}$ of seven published case-control studies, demonstrated that subjects with migraine are at higher risk of having MRI white matter abnormalities (odds ratio 3.9, 95\% CI 2.3 - 6.7) than those without migraine (Figure). In addition, this increased risk is present even in younger individuals who do not have other risk factors for ischemic stroke (odds ratio 3.6, 95\% CI 1.5 - 8.4). While a clear association between migraine and MRI white matter abnormalities has been demonstrated, the significance of these findings is still unclear. The MRI abnormalities may be interpreted as: an incidental finding; accumulated microvascular cerebral damage after repeated migraine attacks; or presymptomatic and/or asymptomatic strokes. Therefore if they are confirmed to be a marker for increased stroke risk, ${ }^{73}$ the MRI white matter abnormalities may be used to identify a migraine subpopulation that is at higher risk for ischemic stroke.

\section{Cortical spreading depression and stroke}

A number of imaging techniques (including positron emission tomography ${ }^{74,75}$ and functional $\mathrm{MRI}^{76}$ ) have demonstrated changes in cerebral blood flow during attacks of MWA that are similar to cortical spreading depression, a phenomenon characterized by marked transient electrochemical and cerebrovascular perturbations within the brain. ${ }^{77}$ One study using perfusion-weighted MRI was unable to confirm these findings. ${ }^{78}$ Despite these important observations, it remains unclear if the vascular changes seen during the migraine aura ${ }^{75}$ are of sufficient magnitude to produce ischemia without the coexistence of additional stroke risk factors or whether they require the invocation of other phenomena, such as: inverse coupling between neuronal activation and ischemia; ${ }^{79}$ mitochondrial abnormalities, ${ }^{80}$ and/or platelet accumulation in hypoperfused cerebral areas. ${ }^{81}$ The alternative hypothesis is that cortical spreading depression may be a manifestation of cerebral ischemia. Evidence supporting this hypothesis includes the observation that endothelin, produced by ischemia, is a potent inducer of cortical spreading depression ${ }^{82}$ and the demonstration that peri-infarct depolarization, ${ }^{83}$ a phenomenon similar to cortical spreading depression, is seen in animal models of stroke. Therefore, it is possible that cerebral ischemia induces cortical spreading depression more often than cortical spreading depression induces cerebral ischemia, providing theoretical support to the empirical observation that stroke may induce MWA more often than MWA induces stroke. ${ }^{63}$

\section{Coagulation and platelet abnormalities}

Coagulation and platelet abnormalities may be important contributors to the migraine process, mediate the causal link between migraine and stroke, or serve as pathological disorders that give rise to both conditions. The relationship between migraine and disorders of hemostasis has been reviewed by Crassard et al ${ }^{84}$ There is inconsistent evidence of increased platelet activation in migraine. ${ }^{85}$ Sarchielli et al ${ }^{86}$ suggest that studies using impediometry on whole blood have demonstrated an increase in the index of platelet function only at the end of migraine attacks. This observation does not preclude the possibility that platelet activation at the end of a migraine attack may contribute to migraine-stroke. Essential thrombocythemia is a specific clinical scenario in which abnormal platelet number and function gives rise to both migraine and stroke, ${ }^{87}$ and this process may be modified by the use of antiplatelet agents. ${ }^{88}$

Evidence linking factor VLeiden mutations with symptoms of migraine was observed in a case-control study that measured activated protein $\mathrm{C}$ resistance and factor $\mathrm{V}$ mutations. ${ }^{89}$ However, this finding has not been confirmed in a large case-control study in Italian children and adolescents experiencing MWA. ${ }^{90}$ Tietjen et $\mathrm{al}^{91}$ have found higher levels of von Willebrand factor (a possible marker of endothelial damage ${ }^{92}$ ) in migraineurs with prior stroke. Hering-Hanit et $\mathrm{al}^{93}$ observed evidence for activation of the coagulation system in MWA by measuring prothrombin factor 1.2. At this time, there is insufficient evidence to establish a definite role of coagulation abnormalities in migraine-stroke, however in individual patients, the coexistence of a coagulation risk factor and migraine may be important. ${ }^{94}$

A significant relationship between antiphospholipid antibodies and migraine was suggested in a seminal report by Levine et al. ${ }^{95}$ A number of case reports have demonstrated a higher occurrence of antiphospholipid antibodies in migraine subjects who experienced episodes of cerebral ischemia or transient focal neurological events. ${ }^{96}$ However, a recent prospective study that looked at $\operatorname{IgG}$ and $\operatorname{IgM}$ anticardiolipin antibodies in MWA $(n=518)$, MwoA $(n=497)$ and controls $(n=366)$ did not observe a statistically significant higher occurrence of anticardiolipin antibodies in migraine. ${ }^{97}$ A large European case-control study of patients with antiphospholipid antibodies $(n=1000)$ demonstrated a higher occurrence of migraine compared to controls only in females. ${ }^{98}$ Tietjen et $\mathrm{al}^{99,100}$ have reported a higher incidence of livedo reticularis in migraine, a condition known to be associated with antiphospholipid antibodies ${ }^{98}$ and stroke. ${ }^{101}$

Therefore, while the relationship of coagulation and platelet abnormalities and migraine remains unclear, in some individuals with migraine-stroke these abnormalities may be an important contributing factor, or in some situations, as in the case of essential thrombocythemia, give rise to both conditions.

\section{Oral contraceptives}

In a recent review, Bousser and Kittner ${ }^{102}$ suggest that the wide reported range of stroke risk associated with the use of oral contraceptives (OCs) may be related to variable control of risk factors and/or stroke definition. In a Dutch population-based, case-control study of women aged 18-49 who used OCs, Kemmeren et $\mathrm{al}^{103}$ observed an increased risk ischemic stroke (odds ratio 2.3, 95\% CI 1.6-3.3). Gillum et al, ${ }^{104}$ calculated a summary relative risk of $1.93(95 \%$ CI, 1.3-2.7) in a recent metaanalysis of population-based studies that controlled for smoking and hypertension. However several other risk-adjusted casecontrol studies did not observe a higher stroke risk among women who use low-dose OCs. ${ }^{105-107}$ In these studies there may be a dose-effect above the 20-30 $\mu$ g estrogen dose, particularly when combined with second-generation progestins. ${ }^{108}$ Therefore, in addition to methodological factors, specific treatment issues such as dose, type of estrogen preparation, or combination of estrogen and progestin may contribute to the variable observed stroke risk associated with use of OCs.

The relationship between use of OCs, migraine and stroke has been recently reviewed by Becker. ${ }^{109} \mathrm{He}$ recommended cautious 
use of OCs in women who experience MWA, older women or those who have other stroke risk factors such as hypertension or smoking. Tzourio ${ }^{28}$ emphasized the compounding of stroke risk in female migraineurs who use OCs and smoke. Using multivariate analysis, Milhaud et $\mathrm{al}^{5}$ demonstrated an increased risk of stroke associated with the use of OCs in 'active migraine' patients less than 45 years of age (odds ratio 2.7 , 95\% CI 1.26.0 ). Gillum et $\mathrm{al}^{104}$ reported an increased adjusted relative risk of ischemic stroke associated with the use of OCs in migraine (adjusted relative risk 3.2, 95\% CI 1.4-7.2), based on a metaanalysis of four case-control studies in four countries. Pooled analysis from two US population-based case-control studies demonstrated a somewhat lower ischemic stroke risk (odds ratio 2.1, 95\% CI 1.2-3.7), ${ }^{105}$ suggesting that the magnitude of ischemic stroke risk may vary by country.

The relative risk of ischemic stroke associated OCs in MWA compared to MwoA has not been well studied. Bickerstaff ${ }^{110}$ suggested that the conversion of MwoA to MWA following the introduction of oral contraceptive might be associated with a higher stroke risk, although this was not confirmed by Chang et $\mathrm{al}^{25}$ in a case-control study. There is a suggestion that the interaction of migraine and use of OCs may be important in young women who experience lacunar infarction. ${ }^{111}$ Therefore, the stroke risk associated with use of OCs in migraine may be viewed as: an independent stroke risk factor; mediated by the induction of MWA by OCs; a consequence of the interaction with other risk factors such as smoking; or may be related to specific mechanisms of stroke such as lacunar infarction. In this regard, the stroke risk associated with use of OCs in migraine subjects with MRI signal abnormalities may be an important area for clinical study.

\section{Cardiac abnormalities}

The relationship of migraine to cardiac abnormalities such as mitral valve prolapse, atrial septal defect and patent foramen ovale has been evaluated in a number of case-control studies. Spence et $\mathrm{al}^{112}$ observed a higher prevalence of mitral valve prolapse in migraine subjects (odds ratio 2.7, 95\% CI 1.2-6.3). However, this relationship is of uncertain significance in the migraine-stroke debate since an increased risk of stroke associated with mitral valve prolapse in young adults was not demonstrated by Gilon et al ${ }^{113}$ (odds ratio $0.59,95 \%$ CI 0.12 2.50). This may be explained in part by the observation that the risk of stroke in mitral valve prolapse may be related to associated cardiac abnormalities such as atrial fibrillation and congestive heart failure. ${ }^{114}$

A recent meta-analysis by Overell et $\mathrm{al}^{115}$ has demonstrated an increased stroke risk associated with isolated atrial septal aneurysm (odds ratio 2.3, 95\% CI 1.5-3.8), isolated patent foramen ovale (odds ratio $1.83,95 \%$ CI 1.2-2.7), and combined atrial septal aneurysm and patent foramen ovale (odds ratio 5.0, 95\% CI 2.4-10.4) in subjects of all ages. In the same study, an even higher risk of ischemic stroke was observed in subjects less than 55 years of age with isolated patent foramen ovale (odds ratio 3.1, 95\% CI 2.3-4.2), and isolated atrial septal aneurysm (odds ratio 6.1, 95\% CI 2.5-15.2). Isolated atrial septal aneurysm is observed more frequently in MWA compared to MwoA or controls, ${ }^{116}$ raising the possibility that MWA may be a consequence of this cardiac abnormality.
In a prospective study of 581 patients with cryptogenic stroke, Lamy et al ${ }^{117}$ demonstrated patent foramen ovale in $46 \%$ and these patients were more likely to experience migraine than the other cryptogenic stroke subjects. In this study migraine did not correlate with the degree of right-to-left shunt. Using transcranial Doppler and intravenous saline injection in an unselected cohort of migraine patients, Anzola et al ${ }^{118}$ demonstrated a significant relationship between patent foramen ovale and MWA but not MwoA. It is unclear if this relationship is the consequence of a common pathogenesis or a shared genetic predisposition. ${ }^{119,120}$ The pathogenesis of migraine in patients with right-to-left shunts has been attributed to microemboli causing endothelial injury and possibly endothelin production ${ }^{82}$ or due to vasoactive chemicals bypassing the pulmonary filter into the systemic circulation. ${ }^{121}$ Several authors have reported complete or partial resolution of migraine following surgical or transcatheter closure of patent foramen, ${ }^{121,122}$ particularly MWA. ${ }^{123}$ A recent meta-analysis by Khairy et al, ${ }^{124}$ suggests that transcatheter closure of patent foramen ovale may be more efficacious than medical management in preventing ischemic stroke. In individual patients the presence of migraine, patent foramen ovale and factor $\mathrm{V}$ Leiden mutation may coexist and lead to stroke. ${ }^{94}$

Therefore, cardiac abnormalities may mediate the relationship between migraine and stroke through a common underlying pathological process or through the induction of MWA as an independent stroke risk factor. The possibility that both may be inherited through a common genetic mechanism requires further study.

\section{CONCLUSION}

A significant nonrandom relationship between migraine and ischemic stroke has been demonstrated in population and casecontrol studies. Magnetic resonance imaging white matter abnormalities are seen more frequently in migraine patients, and may foreshadow the development of ischemic stroke. The association between migraine and stroke has been described by a wide range of definitions that include: migrainous infarction, migraine-induced stroke, and migraine-related stroke. However, the terms are largely descriptive in the absence of sufficient understanding of the underlying pathophysiological mechanisms, and consequently a greater understanding of the specific direction of the causal link in migraine-stroke would likely lead to more valid terminology.

Migraine may occur as a consequence of conditions that are known to predispose to stroke; therefore it remains to be determined whether migraine predisposes to stroke in the absence of any known disease associations, if it is an epiphenomenon of an underlying stroke diathesis, or if it requires the presence of another stroke risk factor to produce cerebral ischemia. Furthermore, it is unclear if ischemia results in migraine more often than migraine results in ischemia. A recent case-control study by Kern et al ${ }^{125}$ suggests that stroke risk factors differ in MWA and MwoA. Migraine with aura patients who developed stroke were more commonly found to have a patent foramen ovale or other cardiac abnormality and OC use compared to MwoA. Conversely, MwoA patients who experienced stroke more commonly were found to have 
hypertension, diabetes, hypercholesterolemia, and coagulopathy compared to MWA. Further clinical studies that evaluate this bidirectional relationship are needed to determine why migraine patients are subject to a higher risk of ischemic stroke. These studies may improve our understanding of basic stroke mechanisms and may suggest an important role for disease management in migraine care. ${ }^{126}$

\section{ACKNOWLEDGEMENTS}

Thanks to Rick Swartz BSc PhD and Ashfaq Shuaib MBBS FRCP $(C)$ for reviewing a draft of this manuscript and for providing helpful suggestions. RZK is a Closure I co-investigator and has provided paid consultative services to, and received speaking honoraria from, AstraZeneca, MerckFrosst, and Jansen-Ortho Biotech.

\section{REFERENCES}

1. Fere C. Contribution a l'etude de la migraine ophthalmique. Rev Med 1861; 1:625-649.

2. Galezowski X. Ophthalmic megrim; an affection of the vasomotor nerves of the retina and retinal center, which may end in thrombosis. Lancet 1881; 1:176-178.

3. Charcot J-M. Sur un cas de migraine ophthalmoplegique. Prog Med 1890; 1:83-84

4. Hunt RJ. A contribution to the paralytic and other persistent sequelae of migraine. Am J Med Sci 1915; 150:313-330.

5. Milhaud D, Bogousslavsky J, van Melle G, Liot P. Ischemic stroke and active migraine. Neurology 2001; 57(10):1805-1811.

6. Arboix A, Massons J, Garcia-Eroles L, et al. Migrainous cerebral infarction in the Sagrat Cor Hospital of Barcelona stroke registry. Cephalalgia 2002; 23:389-394.

7. Dayno JM, Silberstein SD. Migraine-related stroke versus migraine-induced stroke. Headache 1997; 37:463-464.

8. Headache Classification Committee of the International Headache Society. The International Classification of Headache Disorders, 2nd Edition. Cephalalgia 2004; 24(Suppl 1):1-160.

9. Hoekstra-van Dalen RA, Cillessen JP, Kappelle LJ, van Gijn J. Cerebral infarcts associated with migraine: clinical features, risk factors and follow-up. J Neurol 1996; 243(7):511-515.

10. Welch KM, Levine SR. Migraine-related stroke in the context of the International Headache Society classification of head pain. Arch Neurol 1990; 47:458-462

11. Paciaroni M, Parnetti L, Sarchielli P, Gallai V. Headache associated with acute ischemic stroke. J Headache Pain 2001; 2:25-29.

12. Leira R, Davalos A, Aneiros A, et al. Headache as a surrogate marker of the molecular mechanisms implicated in progressing stroke. Cephalalgia 2002; 22:303-308.

13. Jorgensen HS, Jesperson HF, Nakayama H, Raaschou HO, Olsen TS. Headache in stroke: the Copenhagen Stroke Study. Neurology 1994; 44(10):1793-1797.

14. Fisher M. Headache and stroke. Two common disorders or commonality of cause? Arch Intern Med 2003; 163:1005.

15. Brandt T, Steinke W, Thie A, Pessin MS, Caplan LR. Posterior cerebral artery territory infarcts: clinical features, infarct topography, causes and outcome. Multicenter results and a review of the literature. Cerebrovasc Dis 2000; 10(3):170-182.

16. Cals N, Devuyst G, Afsar N, Karapanayiotides T, Bogousslavsky J. Pure superficial posterior cerebral artery territory infarction in the Lausanne Stroke Registry. J Neurol 2002; 249(7):855-861.

17. Barinagarrementeria F, Amaya LE, Cantu C. Causes and mechanisms of cerebellar infarction in young patients. Stroke 1997; 28(12):2400-2404.

18. Demirkaya S, Odabasi Z, Gokcil Z, et al. Migrainous stroke causing bilateral anterior cerebral artery territory infarction. Headache 1999; 39(7):513-516.

19. Merikangas KR, Fenton BT, Cheng SH, Stolar MJ, Risch N. Association between migraine and stroke in a large-scale epidemiological study of the United States. Arch Neurol 1997; 54(4):362-368.
20. Valentgas P, Cole A, Mo J, Walker AM. Triptan use is not associated with increased risk of severe vascular events in migraine patients. Eur J Neurol 2002; 9(Suppl 2):45.

21. Hall GC, Brown MM, Mo J, MacRae D. Migraine, triptan treatment and the risk of cardiovascular disease, stroke and mortality. Eur J Neurol 2002; 9(Suppl. 2):150.

22. Jousilahti P, Tuomilehto J, Rastenyte D, Vartiainen E. Headache and the risk of stroke: a prospective observational cohort study among 35,056 Finnish men and women. Arch Intern Med 2003; 163(9):1058-1062.

23. Buring JE, Hebert P, Romero J, et al. Migraine and subsequent risk of stroke in the Physicians' Health Study. Arch Neurol 1995; 52(2):129-134.

24. Carolei A, Marini C, De Matteis G. History of migraine and risk of cerebral ischaemia in young adults. The Italian National Research Council Study Group on Stroke in the Young. Lancet 1996; 347(9014):1503-1506.

25. Chang CL, Donaghy M, Poulter N. Migraine and stroke in young women: case-control study. The World Health Organisation Collaborative Study of Cardiovascular Disease and Steroid Hormone Contraception. Br Med J 1999; 318(7175):13-18.

26. Schwaag S, Nabavi DG, Frese A, Husstedt IW, Evers S. The association between migraine and juvenile stroke: a case-control study. Headache 2003; 43(2):90-95.

27. Tzourio C, Iglesias S, Hubert JB, et al. Migraine and risk of ischaemic stroke: a case-control study. $\mathrm{Br}$ Med J 1993; 307(6899):289-292.

28. Tzourio C, Tehindrazanarivelo A, Iglesias S, et al. Case-control study of migraine and risk of ischaemic stroke in young women. Br Med J 1995; 310(6983):830-833.

29. Mosek A, Marom R, Korczyn AD, Bornstein N. A history of migraine is not a risk factor to develop an ischemic stroke in the elderly. Headache 2001; 41(4):399-401.

30. Hall GC, Brown MM, Mo J, MacRae D. Triptans in migraine: the risks of stroke, cardiovascular disease, and death in practice. Neurology 2004; 62(4):563-568.

31. Headache Classification Committee of the International Headache Society. Classification and diagnostic criteria for headache disorders, cranial neuralgias, and facial pain. Cephalalgia 1988; 8(Suppl. 7):1-97.

32. Bento MS, Esperanca P. Migraine with prolonged aura. Headache 2000; 40:52-53.

33. Welch KM. Relationship of stroke and migraine. Neurology 1994; 44(10 Suppl 7):S33-S36.

34. Kittner SJ, Stern BJ, Wozniak M, et al. Cerebral infarction in young adults: the Baltimore-Washington Cooperative Young Stroke Study. Neurology 1998; 50(4):890-894.

35. Linetsky E, Leker RR, Ben Hur T. Headache characteristics in patients after migrainous stroke. Neurology 2001; 57(1):130-132.

36. Sochurkova D, Moreau T, Lemesle M, et al. Migraine history and migraine-induced stroke in the Dijon stroke registry. Neuroepidemiology 1999; 18(2):85-91.

37. Henrich J, Sandercock P, Warlow C, Jones L. Stroke and migraine in the Oxfordshire Community Stroke Project. J Neurol 1986; 233(5):257-262.

38. Sacquegna T, Andreoli A, Baldrati A, et al. Ischemic stroke in young adults: the relevance of migrainous infarction. Cephalalgia 1989; 9:255-258.

39. Launer LJ, Terwindt GM, Ferrari M. The prevalence and characteristics of migraine in a population-based cohort: the GEM study. Neurology 1999; 53(3):537-542.

40. Rothrock JF, North J, Madden K, et al. Migraine and migrainous stroke: risk factors and prognosis. Neurology 1993; 43(12):24732476.

41. Donaghy M, Chang CL, Poulter N. Duration, frequency, recency, and type of migraine and the risk of ischaemic stroke in women of childbearing age. J Neurol Neurosurg Psychiatry 2002; 73(6):747-750.

42. Russell MB, Rasmussen BK, Fenger K, Olesen J. Migraine without aura and migraine with aura are distinct clinical entities: a study of four hundred and eighty-four male and female migraineurs from the general population. Cephalalgia 1996; 16:239-245. 
43. Russell MB, Olesen J. A nosographic analysis of the migraine aura in a general population. Brain 1996; 119:355-361.

44. Lykke TL, Kirchmann EM, Faerch RS, et al. An epidemiological survey of hemiplegic migraine. Cephalalgia 2002; 22(5):361375.

45. Bickerstaff ER. Basilar artery migraine. Lancet 1961; 1:15-17.

46. Ohno K, Isotani E, Hirakawa K. MELAS presenting as migraine complicated by stroke: case report. Neuroradiology 1997; 39(11):781-784

47. Berg MJ, Williams LS. The transient syndrome of headache with neurological deficits and CSF lymphocytosis. Neurology 1995; 45:1648-1654.

48. Chabriat H, Vahedi K, Iba-Zizen MT, et al. Clinical spectrum of CADASIL: a study of 7 families. Cerebral autosomal dominant arteriopathy with subcortical infarcts and leukoencephalopathy. Lancet 1995; 346(8980):934-939.

49. Rothrock JF, Walicke P, Swenson MR, Lyden P, Logan WR. Migrainous stroke. Arch Neurol 1988; 45:53-67.

50. Narbone MC, Leggiadro N, La Spina P, et al. Migraine stroke: a possible complication of both migraine with and without aura. Headache 1996; 36(8):481-483.

51. Kupersmith MJ, Vargas ME, Yashar A, et al. Occipital arteriovenous malformations: visual disturbances and presentation. Neurology 1996; 46(4):953-957.

52. Afrridi S, Goadsby P. New onset migraine with a brainstem cavernous angioma. J Neurol Neurosurg Psychiatry 2003; 74:680-683.

53. Verma A, Rosenfeld V, Forteza A, Sharma KR. Occipital lobe tumor presenting as migraine with typical aura. Headache 1996; 36(1):49-52.

54. Dreier JP, Sakowitz OW, Unterberg AW, et al. Migrainous aura starting several minutes after the onset of subarachnoid hemorrhage. Neurology 2001; 57(5):1344-1345.

55. Walker MC, Smith SJ, Sisodya SM, Shorvon SD. Case of simple partial status epilepticus in occipital lobe epilepsy misdiagnosed as migraine: clinical, electrophysiological, and magnetic resonance imaging characteristics. Epilepsia 1995; 36(12):12331236.

56. Bartleson JD, Krecke KN, O’Neill BP, Brown PD. Reversible, strokelike migraine attacks in patients with previous radiation therapy. Neuro -oncol 2003; 5(2):121-127.

57. Modi M, Modi G. Case reports: postpartum cerebral angiopathy in a patient with chronic migraine with aura. Headache 2000; 40(8):677-681.

58. Park-Matsumoto YC, Tazawa T, Shimizu J. Migraine with auralike headache associated with moyamoya disease. Acta Neurol Scand 1999; 100(2):119-121.

59. Heckmann J, Lang C, Weber M, Tomandl B, Neundorfer B. Migraine-like headache as the presenting symptom of basilar artery occlusion. J Headache Pain 2003; 4:37-40.

60. Shuaib A. Stroke from other etiologies masquerading as migrainestroke. Stroke 1991; 22:1068-1074.

61. Tzourio C, Benslamia L, Guillon B, et al. Migraine and the risk of cervical artery dissection: a case control study. Neurology 2002; 59:435-437.

62. Iu P, Lam H. Migrainous spasm simulating carotid dissection: a pitfall in MR arteriographic findings. AJNR Am J Neuroradiol 2003; 22:1550-1552.

63. Olesen J, Friberg L, Olsen TS, et al. Ischaemia-induced (symptomatic) migraine attacks may be more frequent than migraine-induced ischaemic insults. Brain 1993; 116(1):187-202.

64. Schmidt R, Fazekas F, Kleinert G, et al. Magnetic resonance imaging signal hyperintensities in the deep and subcortical white matter. A comparative study between stroke patients and normal volunteers. Arch Neurol 2003; 49:825-827.

65. de Benedittis D, Lorenzetti A, Sina C, Bernasconi V. Magnetic resonance imaging in migraine and tension-type headache. Headache 1995; 36:264-268.

66. Igarashi H, Sakai F, Kan S, Okada J, Tazaki Y. Magnetic resonance imaging of the brain in patients with migraine. Cephalalgia 1991; 11:69-74.

67. Pavese N, Canapicchi R, Nuti A, et al. White matter MRI hyperintensities in a hundred and twenty-nine consecutive migraine patients. Cephalalgia 1994; 14:312-345.

68. Robbins L, Friedman H. MRI in migraineurs. Headache 1992; 32:507-508.

69. Cooney BS, Grossman RI, Farber RE, Goin JE, Galetta SL. Frequency of magnetic resonance imaging abnormalities in patients with migraine. Headache 1996; 36:616-621.

70. Osborn RE, Alder DC, Mitchell CS. MR imaging of the brain in patients with migraine headaches. AJNR Am J Neuroradiol 2003; 12:521-524.

71. Ziegler D, Batnitzky S, Barter R, McMillan JH. Magnetic resonance image abnormalities in migraine with aura. Cephalalgia 1991; 11:147-150.

72. Swartz R, Kern R. Migraine is associated with MRI white matter abnormalities: a meta-analysis. Arch Neurol 2004;61:1366-1368.

73. Vermeer SE, Hollander M, van Dijk EJ, et al. Silent brain infarcts and white matter lesions increase stroke risk in the general population: the Rotterdam Scan Study. Stroke 2003; 34(5):11261129.

74. Diener HC. Positron emission tomography studies in headache. Headache 2003; 37:622-625.

75. Woods RP, Iacoboni M, Mazziotta JC. Bilateral spreading cerebral hypoperfusion during spontaneous migraine headache. New Engl J Med 1994; 331(25):1689-1692.

76. Hadjihani N, Sanchez del Rio M, Wu O, et al. Mechanisms of migraine aura revealed by functional MRI in human visual cortex. Proc Natl Acad Sci U S A 2001; 98(8):4687-4692.

77. Lauritzen $M$. Cortical spreading depression in migraine. Cephalalgia 2001; 21:757-760.

78. Cutrer M, Sorensen AG, Weisskoff RM, et al. Perfusion-weighted imaging defects during spontaneous migrainous aura. Ann Neurol 1998; 43:25-31.

79. Dreier JP, Windmuller O, Petzold G, et al. Ischemia caused by inverse coupling between neuronal activation and cerebral blood flow in rats. International Congress Series 2002; 1235:487-492.

80. Montagna P, Cortelli P, Monari L, et al. 31P-magnetic resonance spectroscopy in migraine without aura. Neurology 1994; 44(4):666-669.

81. Welch KM. Migraine. A biobehavioural disorder. Arch Neurol 1987; 44:323-327.

82. Dreier JP, Kleeberg J, Petzold G, et al. Endothelin-1 potently induces Leao's cortical spreading depression in vivo in the rat: a model for an endothelial trigger of migrainous aura? Brain 2002; 125(1):102-112.

83. Hossmann KA. Periinfarct depolarizations. Cerebrovasc Brain Metab Rev 1996; 8:195-208.

84. Crassard I, Conard J, Bousser MG. Migraine and haemostasis. Cephalalgia 2001; 21(6):630-636.

85. Couch J, Hassanein R. Platelet aggregability in migraine. Neurology 1977; 27(9):843-848.

86. Sarchielli P, Gallai V. Platelets in migraine. J Headache Pain 2003; 2:S61-S66.

87. McIntyre KJ, Hoagland HC, Silverstein MN, Petitt RM. Essential thrombocythemia in young adults. Mayo Clin Proc 1991; 66(2):149-154.

88. Bousser MG, Conard J, Lecrubier C, Bousser J. Migraine or transient ischemic attacks in a patient with essential thrombocythaemia. Treatment with ticlopidine. Ann Med Interne(Paris) 1980; 131(2):87-90.

89. Kontula K, Ylikorkala A, Miettinen H, et al. Arg506Gln factor V mutation (factor $\mathrm{V}$ Leiden) in patients with ischaemic cerebrovascular disease and survivors of myocardial infarction. Thromb Haemost 1995; 73(4):558-560.

90. Soriani S, Borgna-Pignatti C, Trabetti E, et al. Frequency of factor $\mathrm{V}$ Leiden in juvenile migraine with aura. Headache 1998; 38(10):779-781.

91. Tietjen GE, Al Qasmi MM, Athanas K, Dafer RM, Khuder SA. Increased von Willebrand factor in migraine. Neurology 2001; 57(2):334-336.

92. Mannucci PM. von Willebrand factor. A marker of endothelial damage? Arterioscler Thromb Vasc Biol 1998; 18:1359-1362.

93. Hering-Hanit R, Friedman Z, Schlesinger I, Ellis M. Evidence for 
activation of the coagulation system in migraine with aura. Cephalalgia 2001; 21(2):137-139.

94. Heckmann J, Lang C, Dietrich W, Neidhart B, Neundorfer B. Symptomatic migraine linked to stroke due to paradoxical embolism and elevated thrombosis risk. Cephalalgia 2002; 22:154-156.

95. Levine SR, Joseph R, D'Andrea G, Welch KM. Migraine and the lupus anticoagulant. Cephalalgia 1987; 7:93-99.

96. Hogan MJ, Brunet DG, Ford PM, Lillicrap D. Lupus anticoagulant, antiphospholipid antibodies and migraine. Can J Neurol Sci 1988; 15:420-425.

97. Tietjen GE, Day M, Norris L, et al. Role of anticardiolipin antibodies in young persons with migraine and transient focal neurologic events: a prospective study. Neurology 1998; 50(5):1433-1440.

98. Cervera R, Piette JC, Font J, et al. Antiphospholipid syndrome: clinical and immunologic manifestations and patterns of disease expression in a cohort of 1,000 patients. Arthritis Rheum 2002; 46(4):1019-1027.

99. Tietjen GE, Al Qasmi MM, Shukairy MS. Livedo reticularis and migraine: a marker for stroke risk? Headache 2002; 42(5):352355.

100. Tietjen GE, Gottwald L, Al Qasmi MM, Gunda P, Khuder SA. Migraine is associated with livedo reticularis: a prospective study. Headache 2002; 42(4):263-267.

101. Rebollo M, Val F, Garijo F, Quintana F, Berciano J. Livedo reticularis and cerebrovascular lesions (Sneddon's syndrome). Clinical, radiological, and pathological features in eight cases. Brain 1983; 106:965-979.

102. Bousser MG, Kittner SJ. Oral contraceptives and stroke. Cephalalgia 2000; 20(3):183-189.

103. Kemmeren JM, Tanis BC, van den Bosch MAAJ, et al. Risk of Arterial Thrombosis in Relation to Oral Contraceptives (RATIO) Study. Stroke 2002; 33:1202-1208.

104. Gillum LA, Mamidipudi SK, Claiborne JS. Ischemic stroke risk with oral contraceptives. a meta-analysis. JAMA 2000; 284:7278.

105. Schwartz SM, Petitti DB, Siscovick DS, et al. Stroke and use of low-dose oral contraceptives in young women: a pooled analysis of two US studies. Stroke 1998; 29(11):2277-2284.

106. Siritho S, Thrift A, McNeil JJ, et al. Risk of ischemic stroke among users of the oral contraceptive pill. Stroke 2003; 34:1575-1580.

107. Petitti DB, Sidney S, Bernstein AL, et al. Stroke risk in users of low-dose oral contraceptives. New Engl J Med 1996; 335:8-15.

108. Lidegaard O, Kreiner S. Contraceptives and cerebral thrombosis: a five-year national case-control study. Contraception 2002; 65(3):197-205

109. Becker WJ. Use of oral contraceptives in patients with migraine. Neurology 1999; 53(4 Suppl 1):S19-S25.

110. Bickerstaff ER. Neurological Complications of Oral Contraceptives. Oxford: Oxford University Press. 1975.

111. Salobir B, Sabovic M, Peternel P, Stegnar M, Grad A. Classic risk factors, hypercoagulability and migraine in young women with cerebral lacunar infarctions. Acta Neurol Scand 2002; 105(3):189-195.

112. Spence JD, Wong DG, Melendez LJ, Nichol PM, Brown JD. Increased prevalence of mitral valve prolapse in patients with migraine. Can J Neurol Sci 1984; 131(12):1457-1460.

113. Gilon D, Buonanno FS, Joffe MM, et al. Lack of evidence of an association between mitral-valve prolapse and stroke in young patients. New Engl J Med 1999; 341:8-13.

114. Orencia AJ, Petty GW, Khandheria BK, et al. Risk of stroke with mitral valve prolapse in a population-based cohort study. Stroke 1995; 26:7-13.

115. Overell JR, Bone I, Lees KR. Interatrial septal abnormalities and stroke: a meta-analysis of case-control studies. Neurology 2000; 55(8): 1172-1179.

116. Carerj S, Narbone MC, Zito C, et al. Prevalence of atrial septal aneurysm in patients with migraine: an echocardiographic study. Headache 2003; 43(7):725-728.

117. Lamy C, Giannesini C, Zuber M, et al. Clinical and imaging findings in cryptogenic stroke patients with and without patent foramen ovale: the PFO-ASA Study. Atrial Septal Aneurysm. Stroke 2002; 33(3):706-711.

118. Anzola GP, Magoni M, Guindani M, Rozzini L, Dalla VG. Potential source of cerebral embolism in migraine with aura: a transcranial Doppler study. Neurology 1999; 52(8):1622-1625.

119. Arquizan C, Coste J, Touboul PJ, Mas JL. Is patent foramen ovale a family trait? A transcranial Doppler sonographic study. Stroke 2001; 32:1563-1566.

120. Angeli S, Carrera P, Del Sette M, et al. Very high prevalence of right-to-left shunt on transcranial Doppler in an Italian family with cerebral autosomal dominant angiopathy with subcortical infarcts and leukoencephalopathy. Eur Neurol 2001; 46(4):198201.

121. Wilmshurst PT, Nightingale S, Walsh KP, Morrison WL. Effect on migraine of closure of cardiac right-to-left shunts to prevent recurrence of decompression illness or stroke or for haemodynamic reasons. Lancet 2000; 356(9242):1648-1651.

122. Morandi E, Anzola GP, Angeli S, Melzi G, Onorato E. Transcatheter closure of patent foramen ovale: a new migraine treatment? J Interv Cardiol 2003; 16(1):39-42.

123. Sztajzel R, Genoud D, Roth S, Mermillod B, Floch-Rohr J. Patent foramen ovale, a possible cause of symptomatic migraine: a study of 74 patients with acute ischemic stroke. Cerebrovasc Dis 2002; 13(2):102-106.

124. Khairy P, O'Donnell CP, Landzberg MJ. Transcatheter closure versus medical therapy of patent foramen ovale and presumed paradoxical embolization. Ann Int Med 2003; 139:753-760.

125. Kern R, Gilani A, Jaigobin C. Migraine-stroke: analysis of risk factors in migraine with and without aura. 2004;(Abstract American Headache Society, June 2004)

126. Loder E, Biondi D. Disease modification in migraine: a concept that has come of age? Headache 2003; 43:135-143. 